\title{
Energy Management of People in Organizations: A Review and Research Agenda
}

\author{
Michaéla C. Schippers • René Hogenes
}

Published online: 3 May 2011

(c) The Author(s) 2011. This article is published with open access at Springerlink.com

\begin{abstract}
Although energy is a concept that is implied in many motivational theories, is hardly ever explicitly mentioned or researched. The current article first relates theories and research findings that were thus far not explicitly related to energy. We describe theories such as flow, subjective well-being, engagement and burn-out, and make the link with energy more explicit. Also, we make a first link between personality characteristics and energy, and describe the role of leadership in unleashing followers' energy. Following, we identify how the topic of energy management can be profitably incorporated in research from a scientific as well as a practitioner viewpoint. Finally, we describe several interventions to enhance energy in individuals and organizations.
\end{abstract}

Keywords Energy · Review - Intervention - Time management $\cdot$ Positive psychology $\cdot$ Leadership

"In organizations real power and energy is generated through relationships. The patterns of relationships and the capacities to form them are more important than tasks, functions, roles and positions"-Margaret Wheatley.

Energetic employees are imperative for an organization's success. People with a lot of energy are more

\author{
M. C. Schippers $(\bowtie)$ \\ Rotterdam School of Management, Erasmus University \\ Rotterdam, PO Box 1738, 3000 DR Rotterdam, The Netherlands \\ e-mail: mschippers@rsm.nl \\ R. Hogenes \\ Uw Energiecoach B.V., Postbus 66, 3740 AB Baarn, \\ The Netherlands \\ e-mail: info@uwenergiecoach.nl
}

productive, creative and they have a positive influence on others (Ash 1913; Cross et al. 2003; Cross and Parker 2004). When there is a high energy level within an organization, everything seems to happen more easily. Employees stimulate each other by continuously giving that extra bit of effort, and of course, this is also positive for the organization (cf. Bruch and Ghoshal 2003; Cross and Parker 2004). Although in Eastern philosophy "Qi" (life power or energy flow) is a pervading concept that is often mentioned in relation to physical and mental health and fitness, in Western philosophy and theory it remains more implicit. Although early psychologists (e.g., Freud) and sociologists (e.g., Ash) mentioned human energy in relation to mental and physical health, later theories hardly ever mentioned nor measured energy explicitly. Since the beginning of this century, this is starting to change and more attention is being paid to positive psychology (Seligman and Csikszentmihalyi 2000), the study of positive social interactions for optimal human functioning (e.g., Heaphy and Dutton 2008). Many motivational constructs do imply energy, but still hardly ever explicitly mention it. Only few studies have directly measured energy and its effects (e.g., Bruch and Ghoshal 2003; Cross et al. 2003; Ryan and Frederick 1997).

Thus although in the management and psychology literature, many theories seem to have a more or less energetic implications, most theories do not explicitly mention energy levels as part of the theory. Theory and research regarding burnout (e.g., Maslach and Schaufeli 1993) can be seen as concerning a lack of energy, more specifically exhaustion at the physical, emotional and cognitive level, due to being exposed to stressors for a prolonged period of time (for a review see Maslach et al. 2001). Even in those theories, energy is often not explicitly mentioned, but the lack of energy is referred to as "emotional depletion". 
A lack of energy is also discussed in theory and research regarding emotional dissonance (i.e. the conflict between inner real feelings and required or shown feelings; (Middleton 1989), and emotional labor (Brotheridge and Lee 2003; Grandey 2003; Morris and Feldman 1996). In jobs with a lot of emotional dissonance, requiring emotional labor, energy may be drained quickly and may lead to a downward spiral of energy loss (van Gelderen et al. 2007), or even burnout (Bakker and Heuven 2006).

Examples of theories describing energy gains more explicitly are engagement, or a positive work-related state, characterized by vigor, dedication and absorption (Gonzalez-Roma et al. 2006; Schaufeli et al. 2002), the somewhat less well-known theories of thriving, or "the psychological state in which individuals experience both a sense of vitality and a sense of learning at work" (Spreitzer et al. 2005, p. 538), and human flourishing (Fredrickson and Losada 2005).

In the current paper, we will first define energy, describe the literature in this emerging field, and discuss concepts that have an energetic connotation, such as "flow" (Csikszentmihalyi 1990; Csikszentmihalyi and LeFevre 1989), "engagement and burn-out" (Gonzalez-Roma et al. 2006; Schaufeli et al. 2006), "emotional dissonance" (Morris and Feldman 1996), "thriving and flourishing" (Fredrickson and Losada 2005; Spreitzer et al. 2005), "time management" (Adams and Jex 1999; Macan 1994), "work recovery" (Sonnentag 2003), and "conservation of resources" (Hobfoll 1989). Next, we will describe an energy enhancing intervention. Throughout, an important goal of the article is to offer a research agenda next to the review of the literature.

\section{Definition of Energy}

Energy can be defined as "a type of positive affective arousal, which people can experience as emotion-short responses to specific events-or mood-longer-lasting affective states that need not be a response to a specific event" (Quinn and Dutton 2005, p. 36).

Energy can be both a short-term and a long-term process. Just like for instance satisfaction, people can experience long-term (basic energy level) as well as short-term effects on their energy level. Long-term draining effects can result in a burnout, and should probably be viewed as deviations from a persons' basic energy level. Research regarding flow defined as "the way people describe their state of mind when consciousness is harmoniously ordered, and they want to pursue whatever they are doing for its own sake" (Csikszentmihalyi 1990, p. 6), shows that people can be completely focused and energetic in all domains, be it sports, games, hobbies, or work. This complete immersion in an activity is the result of the focusing of mental energy on an activity which is liked by the actor. Flow is a source of mental energy, in that it focuses attention and motivates action. However, an important reason why people often lack energy is that they have trouble determining what they really like and even if they know what activities they like best, fail to seek out these activities more often. In order to become more energetic Csikszentmihalyi (1997, p. 127) advises:

"We must then transfer some psychic energy each day from tasks that we don't like doing, or from passive leisure, into something we never did before, or something we enjoy doing but don't do often enough because it seems too much trouble."

\section{Energy Level}

Practitioners often deal with workers who are seeking to maintain an optimal energy level, despite the stressors they have to deal with on a daily basis. In this respect, energy can be seen as a valued resource that people strive to retain, protect, and/or gain (Hobfoll 1989). Three kinds of energy are often discerned, namely (a) mental energy (being able to intensely focus), (b) physical energy (strength, endurance, flexibility), and (c) emotional energy (being in touch with one's own feelings and core values). These are similar to, but seemingly the antipodes of the dimensions of burnout (Maslach et al. 2001). Within the energy dimensions, three characteristics of energy can be discerned, namely the amount, stability, and direction of the energy.

For instance, when a person has a high amount of mental energy, but stability and direction are low, then this person can focus intensely on a task, but only for a short period of time and without much direction, and often this will not lead to great results. However, if a person has a clear direction of energy, and is aware of the low stability, this can be dealt with by short bouts of intense focused actions. On the other hand, having to "keep up appearances" at work, creating a façade of conformity, while ones personal values differ, may be a drain in terms of emotional energy (Hewlin 2003).

Extensive experience in energy management training sessions of the second author show that having a lot of physical energy is no guarantee of success when the stability of energy is not in order. No matter the amount of energy, without direction of energy, problems will occur, as the energy is not linked to targets, but to random actions without higher target or link to the mission. This is also mentioned by Cross and Parker (2004), where they discuss the role of "energizers" in their research, opposing them to "de-energizers". Energizers are trustworthy people in the organization (not necessarily managers), that have a 
compelling vision and are able to convince others around them to work towards this mission. De-energizers are the black holes of an organization, draining the energy of their co-workers and leaders. This may have to do with personality characteristics of the person (e.g., Burke and Witt 2004), or their specific behavior. According to Cross et al. (2003, see also Cross and Parker 2004), especially political behaviors can be extremely draining. Network analyses by Cross et al. (2003) showed that energizers and de-energizers can have a powerful influence on the performance of people around them (see also Leiter and Maslach 1988). People experiencing a burnout can also negatively influence the energy of others in the workplace, by means of contagion (Maslach et al. 2001).

How then can we make sure to be energized and energize others? What are the factors that play a role in energizing? In the next sections we will describe personal characteristics and behaviors that discern energizers from de-energizers.

\section{Personality, Behavior, and Leadership Styles}

What discerns people and managers high on energy from people low on energy? Are people high on energy better in touch with their feelings, and hence make the right choices? Are they better in prioritizing and do they therefore have more energy? Or is it just because people high on energy do the things they like, and are good at, so that work does not feel like work?

Energetic people achieve their goals sooner, and enjoy the road to these goals better. Indeed better person-job fit has been related to a higher level of engagement and less burn-out (Chilton et al. 2005; for a review see Maslach et al. 2001). Also, having a clear goal is a prerequisite to the focusing of energy (Csikszentmihalyi 1997). At the same time, the behavior of energetic people can be contagious for the productivity of others in their immediate surroundings (Bakker et al. 2005).

Although some questions are answered relating to recovery and work-life balance (e.g., Sonnentag 2001, 2003), many questions relating to how we can get less drained during work hours are still not answered. The extent to which people cope with stressors, or let energy drains rule their lives is an important variable in maintaining energy, and the relationships surrounding these is an important research question (Cross et al. 2003; Cross and Parker 2004). In this respect, the notion of energy enhancers, people that energize others around them, may be an interesting starting point. How is energy spread through a network? At the same time the concept of energy enhancers may have some overlap with the concept of subjective well-being (Diener 1984), as people high on subjective well-being may also be high on energy. Research has indeed shown a positive relationship between vitality and well-being (Ryan and Frederick 1997). At the same time, being high on energy may be distinct from energizing others, although being high on energy yourself may be a requirement.

Organizational energy often starts with the energy of a few key figures (Bruch and Ghoshal 2003). Transformational leaders are traditionally considered as energizing: the idea is that transformational leaders are able to inspire others and change the way people work toward a common goal (cf. Bass 1985; Kark and Van Dijk 2007; Yukl 1998). For instance, research among 32 teams from various kinds of industries has shown that teams with a transformational leader are more likely to have a shared vision, which in turn relates to more team reflexivity (i.e., the process of reflecting on and adapting of goals, strategies, and processes) in turn enhancing team performance (Schippers et al. 2008). The behavioral component underlying the success of transformational leadership may be regulatory focus theory (Higgins 1998; Kark and Van Dijk 2007). Within this theory, two motivational orientations are discerned, promotion focus, referring to a more "risky" information processing style, while prevention focus is related to a more risk-averse and vigilant processing style (Higgins 1998). Promotion goals refer to ideals, hope, and aspirations, while prevention goals refer to duties, responsibilities, and things that ought to be done (Kark and Van Dijk 2007). People with a promotion focus are more creative problem-solvers (Friedman and Förster 2001), are more willing to take risks, and may be better able to energize people around them towards compelling goals (cf. Brockner and Higgins 2001; Crowe and Higgins 1997). Promotion focus seems a more energetic style (i.e., vision, hope), while prevention focus may be related to a de-energizing style (i.e., always seeing roadblocks and reasons why projects will fail). A transformational leadership style may very well be related to a promotion focus, while a transactional leadership style may be more related to a prevention focus, and hence transformational leaders may be better able to energize followers into action toward a common goal (Kark and Van Dijk 2007). The effects of transformational leadership may thus be mediated by the energy they create towards this common goal. Research has shown that the success of a promotion or prevention appeal is dependent on the fit between leaders and followers regulatory focus (Stam et al. 2010). Although we do not know of any research explicitly investigating the role of promotion versus prevention focus in enhancing or diminishing energy level, people with a promotion focus may be more goal oriented (e.g., possible gains) and less distracted by thoughts of what they ought to do, or ruminating about failure (e.g., possible losses), while people 
with a prevention focus will be more inclined to ruminate about possible losses and spend time on counterfactual thinking (Roese et al. 1999). Consequently, people with a promotion focus will be better able to focus their energy on the goal and be more productive. This may be a viable route for future research to determine the relationship between leadership, regulatory focus, and followers' energy.

A related personal characteristic may be personal initiative (Frese and Fay 2001), or proactive behavior (Bateman and Crant 1993). Persons high on proactive behavior are more inclined to take charge (Morrison and Phelps 1999), overcome barriers and deal proactively with demands (Frese and Fay 2001; Sonnentag 2003). Proactive behavior has been related to a reflexive style of thinking in teams (Schippers et al. 2007). Research has shown that proactive behavior is related to work recovery. A study among 147 employees of six public service organizations showed that recovery after work had a positive effect on work engagement the next day, and in turn taking initiative and pursuing learning goals at work (Sonnentag 2003). Thus, being able to rest and recover after work is important for energetic behavior in the form of taking initiative and learning during the work day.

A personality variable that may be negatively related to energy at work is neuroticism, or emotional instability. Neurotic individuals may waste a lot of energy, because they are inclined to ruminate excessively (Nolan et al. 1998; cf. Eisenberger et al. 2005), especially when they are under stress. Research among 109 out-patients suffering from unipolar depressive disorder has shown that neuroticism is related to dysfunctional ruminating and subsequent depression as reactions to stress (Lam et al. 2003). Interestingly, "analyze to understand" was the only rumination subscale not related to depression in their research (Lam et al. 2003). Other research has related neuroticism to fatigue (Calderwood 2009) and burnout (for a review see Maslach et al. 2001). This research suggests that neurotic individuals may be inclined to waste their energy in dysfunctional ruminating, leading to a lowered energy level, fatigue, and in extreme cases depression.

Other personality characteristics related to energy at work may be agreeableness, conscientiousness, and selfesteem. Workers high in conscientiousness are reliable, methodical, disciplined, and organized, while workers high on agreeableness are cooperative, helpful, and tolerant (Costa and McCrae 1992). People high on agreeableness and low on self-esteem will have trouble saying no (cf. Joseph 2000; Judge and LePine 2007). If these persons are also high on conscientiousness, they will not only have trouble saying "no" to requests, but will also most likely act on their promise (Costa and McCrae 1992). These workers may be so busy fulfilling other people's requests, that they do not have enough time left to do the things needed for achieving their own results. Consequently, in the long-term, this may result in energy loss and burnout. Although not investigated in combination, research by Ryan and Frederick (1997) found extraversion and conscientiousness to be negatively related to vitality, and neuroticism to be positively related to vitality.

Intra-individual combinations of conscientiousness and agreeableness may explain "high maintenance"-chronic annoying and de-energizing-behavior in the workplace (Burke and Witt 2004). This "high maintenance" behavior tends to exhaust supervisors and co-workers of their morale, energy, and time, while at the same time driving high-performing co-workers out of an organization (Grensing-Pophal 2001; Principe 1997). Research among 336 clerical workers in a production organization showed that workers with high or low conscientiousness combined with low agreeableness received higher scores on supervisor rated high maintenance behavior. In contrast, workers with a combination of high conscientiousness and high agreeableness received the lowest ratings of high maintenance behavior, and were experienced as least de-energizing (Burke and Witt 2004). This research suggests that different combinations of personality will result in energizing or de-energizing behavior. Future research could investigate the functional and dysfunctional role of personality with respect to energy. For instance, extraversion and openness to experience have not been explicitly related to energy before. Since the relation between personality and subjective well-being has been extensively researched (for reviews see (DeNeve and Cooper 1998; Diener et al. 1999), this may be a good starting point for related research regarding personal energy level and energizing behavior.

\section{Relation to Career Success}

Are people high on energy also more successful in their careers (and lives)? If yes, what are those factors that determine this? To our knowledge, there is no scientific evidence showing this relationship. However, research on expert performance showed that long-term success in any discipline is determined by the actual time an individual works at his or her most important goals on a weekly basis, and that it takes 10 years of deliberate practice before a person can really excel in a specific discipline (e.g., chess; Ericsson et al. 1993). Other research has looked at the differences between "superworkers" and moderate performers. For instance, research among 40 software designers, comparing "superworkers" (who seem to be able to focus their energy toward important goals), and moderate performers, showed that high performers spent more time on local planning and feedback processing, 
whereas moderate performance were more engaged in analyzing requirements and verbalizing task-irrelevant cognitions, such as ruminating about possible failure (Sonnentag 1998). Similar effects have been found for expert performance (for a review see Ericsson and Lehmann 1996). Experts spend a considerable amount of energy focusing on becoming the best in their discipline, and are highly motivated by their goal. This is so much so, that they economize on social interactions, and as a consequence are often seen as self-centered during their (sports) career (Jones 2006).

Although not everyone will want to become a top performer, this research is informative in showing how one can stay energized while reaching the goals in work and life. Even when people have a clear goal, it is sometimes hard to stay focused. The question then is: how can a task focus be enhanced? Two things may play a role here: (a) The extent to which a person reflects on his/her short and long-term goals and (b) the extent to which the person reflects on the consequences of this goal for everyday actions.

\section{Awareness of Energy: Reflection on Energy Might Help Refocusing}

The complaint of modern times is that we do not have time and that we are busy all the time. However, closer inspection of what people really do reveals that most people waste a lot of time instead of doing what they really need or want to do. For instance, research among managers of a global airline company and a large oil company, showed that that fully $90 \%$ of them wasted time and productivity, despite having well-defined objectives and goals (Bruch and Ghoshal 2002). The researchers assert that the reason for this productivity and energy loss (which they dubbed "active non-action") is a perceived lack of personal discretion or control. Note that these were all managers, who are generally seen as having more freedom in setting their goals and ways to achieve them then subordinates. These managers mistakenly thought they had no choice in for instance canceling meetings, having to talk to people, and did not reflect on how to spend their time most effectively. In contrast, successful managers were the ones that did take initiative and acted on opportunities (Bruch and Ghoshal 2003). Only $10 \%$ of the managers in the oil company spent their time in a committed, purposeful, and reflective manner (Bruch and Ghoshal 2002). Those managers were able to focus in a proactive way: having reflected on what their goal was, they did not get sidetracked by all kinds of distractions, such as e-mail, meetings, and unforeseen demands. This suggests that workers that reflect on a most efficient use of their time will use their energy better and more effectively than those that don't.

Indeed, performance improvement in all kinds of domains may be achieved through a process of reflexivity-reflecting upon work processes and performance (Schippers et al. 2007; West 1996, 2000). For instance, research among 73 student teams showed that teams reflecting on their performance after detrimental initial performance were able to improve final team performance (Schippers and Homan 2009). Furthermore, research among teams in hospitals, having much discretion, showed that teams that were more reflexive, were better able to deal with, and reacted more innovatively with respect to the demands of workload and demanding work facilities (Schippers et al. 2010). Together, this research suggests that reflexivity may be important in (a) realizing the real amount of discretion people has, and (b) their ability to change and refocus the situation. This may be energizing in the sense that people will try to actively change the situation, instead of a "learned helplessness" attitude (Abramson et al. 1978). In a sense, the underlying mechanism in the above findings may be that reflexivity helps in becoming aware of things that can be changed and improved, and a subsequent refocusing of energy towards this (new) goal.

\section{Measurement and Research Agenda}

Energy could be measured by asking people what kind of work gives them most satisfaction, how often they perform these tasks, how well they achieve their goals, and how much time they spend on recovery from work, including physical activities. Also, how energetic people feel, and how involved they are during work hours, and how much energy drains they experience at work. We discussed the possible role of leadership in this respect. Recent research regarding leadership suggests that servant leadership, with its' focus on others instead of the organization (Nuijten 2009; Stone et al. 2004; van Dierendonck and Nuijten in press), may also be a viable route for future research in relation to unleashing followers energy. On the basis of the above review, future research could explore (a) what discerns people high on energy from people low on energy? (b) are people high on energy/well-balanced also more successful in their careers (and lives)? and, if yes, (c) what are effective tools that can help, and (d) how can an intervention be developed to make sure that, in principle, everyone can reach this success (not just the "lucky few" who happened to reach this).

Summarizing, in the above we have raised several questions that future research could help to answer. These include: 
- How can energy best be measured?

- Are people high on energy also energizers? Or are these constructs relatively independent? Is being high on energy a prerequisite for being an energizer? What is the role of these energizers in unleashing organizational energy?

- What personality variables are highly related to energy? Is there a combination of personality traits that is most strongly related to energy?

- How does energy flow through networks in organizations?

- Is energy related to subjective well-being?

- What is the role of leadership in unleashing followers' and organizational energy? How does the combination of transformational or servant leadership and regulatory focus affect followers energy? What is the role of regulatory fit in this respect?

Next to research looking at determinants and outcomes of energy, as was outlined above, the effects of possible interventions should be assessed. As Maslach et al. (2001) noted limitations in study design, especially the lack of control groups and longitudinal studies limits the extent to which research findings regarding the effect of interventions can be interpreted. Future research could incorporate the level of energy both before and after an intervention, and especially the long-term effects of such interventions. Below, we will describe what is known about energy enhancing interventions, and describe what an effective intervention could look like.

\section{Practical Tools that Help in Creating and Maintaining Energy}

Several practical tools could be helpful in preserving energy during the work day. Some questions that research could answer are: What are the most effective tools that can help in energy management? For instance, does the use of formalized tools such as Outlook, to-do lists, add or detract from workplace stress? Does the practice of "blocking one's calendar out", so that others cannot put surprise meetings on, work in this respect? Is there a "perfect combination" of tools one can use, and if yes, which one works best? ${ }^{1}$

On the basis of the experience of the second author, who is an experienced trainer in energy and time-management, three main practices can be discerned that work well: (1) Planning according to result areas, (2) reflect on long-term goals, and (3) physical fitness.

\footnotetext{
${ }^{1}$ We thank the special issue editor Allan Church for suggesting this research question to us.
}

Planning According to Result Areas

First, it is important to plan according to result areas (acquisition, finance, innovation) instead of on random actions. This makes planning survey-able and resultoriented. Doing so, the random actions will be prioritized and ordered within the appropriate result-area. For instance, in science two large result areas are teaching and research, which can of course have several result areas as part of these two broad areas, such as different research projects. Successful workers are capable of making important things urgent, and make sure to spend time on these tasks on a daily basis (cf. Ericsson and Lehmann 1996; Hall and Hursch 1982). Spending time on important tasks every day is more effective than "blocking one's calendar out" sometimes, because for most workers these days are rare and do not provide enough time to make progress on important tasks. In the long run, it is much more efficient to do a few big things (e.g., making progress toward the goals within the result areas, than do a lot of small things without a direct measurable consequence towards main goals (cf. Hall and Hursch 1982).

Most people get sidetracked by the urgency principle, where deadlines, e-mails, and meetings determine their daily actions. Interruptions can be very disruptive for the work flow (Fisher 1998). Although workers sometimes get something out of interruptions, if they are triggered often to switch to other result areas, they lose energy because of time they need to refocus their attention. Sometimes, they even forget what they were doing and get sidetracked altogether (Fisher 1998; Mark et al. 2005; O'Conaill and Frohlich 1995). An important distraction may come from the frequent e-mails we get. As most of us experience, it is easy to get side-tracked by e-mails. We see a pop-up whenever a new e-mail comes in and we are inclined to react right away, or at least read it. However, each interruption takes about $7 \mathrm{~min}$ of a person's concentration. Checking your mail for instance eight times a day results in a time loss of more than $1 \mathrm{~h}$ each day. Most people see e-mail as an urgent task, so they lose a lot of energy through diminished concentration, less focus and less flow experience. A tip to reduce getting side-tracked by e-mails is to open e-mails only at specific time points, for instance twice a day, at $10 \mathrm{AM}$ and $2 \mathrm{PM}$. If you do, reply instantly to mail you can deal with within 2 min and drag other mail to your result areas. You can deal with these mails as soon as you plan to work on that specific area.

\section{Intervention}

How can we develop an intervention to make sure that, in principle, everyone can reach this state of "high energy", 
or refocusing of energy to become more productive? Although there is some evidence with respect to burnout, showing that an intervention aimed at restoring equity can be successful, especially when support from co-workers and supervisors is high (van Dierendonck et al. 1998), research investigating the effects of "energy management" interventions is scarce. We refer to energy management interventions in a broad sense, such as time-management courses, health interventions, and similar interventions that can have as a (main or side) goal to enhance energy. Most interventions are aimed at only one or two aspects (for a review see van der Hek and Plomp 1997). Research regarding the use of time management techniques such as setting goals and priorities, making lists and schedules, and a preference for organization, were shown to be helpful in reducing tension and increasing job satisfaction, although a relation with job performance was not found (Macan 1994). Furthermore, time management techniques seemed effective in reducing stress due to work-family conflict (Adams and Jex 1999). A recent meta-analysis of stressmanagement studies revealed that cognitive-behavioral interventions were more successful in reducing stress, than for instance relaxation and meditation (Richardson and Rothstein 2008). Surprisingly, combining different interventions led to a reduced effect size. Also, longer programs were not more effective than shorter programs (Richardson and Rothstein 2008). However, more research is needed to test the combined effects of different combinations of interventions, such as time-management, relaxation, and physical exercise in enhancing energy. Most of the research done so far, is aimed at reducing stress or the negative effects of burnout, while interventions specifically aimed at enhancing or maintaining energy are scarce (for an example of burnout prevention and engagement enhancement interventions, see Leiter and Maslach 2000). This may in part be two sides of the same coin, although the overlap may not be perfect, as was found for the relation between burnout and engagement (cf. Schaufeli and Bakker 2004). In their study, Schaufeli and Bakker (2004) found that burnout and engagement shared between 10 and 25 percent of variance, both were in part predicted by different variables, and also differed with respect to outcomes. This may have important consequences for the effectiveness of interventions, depending on what the goal of the intervention is; either reducing/preventing burnout, or enhancing/maintaining a high energy level. This is a viable route for future research.

\section{Interventions in Practice}

A problem that many trainers notice in organizations is that often people are sidetracked from their goals, and consequently get feedback from their managers that goals are not met. Sometimes there is a lack of motivational energy, stress-management, time-management, problem solving ability and/or physical energy. An intervention may start by asking workers to extrapolate the results of their actions in the future for say 5 or 10 years. This may make the unwanted end result of their day-to-day actions visible, and helps them to reflect on possible changes in order to redirect their energy. The workers can then find out what motivates him or her to give the full $100 \%$ in his/her work (cf. Csikszentmihalyi 1997). A coach or trainer can then give some tools to enhance and maintain that motivation. In this way, competencies are used and developed instead of wasting energy on tasks that do not fit the person (i.e., Edwards 1991). A personal energy plan can then be developed, including the use of formalized tools.

\section{Reflecting on Long-Term Goals}

Reflecting on and determining long-term goals, is an important prerequisite for effective energy management. A problem is that most people are driven by the need for instant success (doing small things, and getting rewarded immediately) which has a stronger pull than long-term success, with delayed gratification of rewards (e.g., Mischel 1996; Muraven and Baumeister 2000). In order to get bigger time-consuming jobs done that contribute to longer-term goals (e.g., publishing articles in top journals) it is recommended to plan a unit of time every day for these activities that are important, but not (yet) urgent. If organizations are capable to make parameters to measure progress toward long-term goals, than this will have a powerful drive for workers to really act upon their main organizational values and goals on a daily basis. Instead if workers do what the average person is inclined to do, they get average results (cf. Sonnentag 1998).

\section{Physical Fitness}

In order to maintain energy at the long-term and maintain physical fitness (especially when one has a desk-job), it is important to make exercising a top priority. Research has shown that besides low-effort activities such as watching television, taking a bath, and social activities, physical activities in leisure time have a positive effect on work recovery (Sonnentag 2001). Indeed, research has shown that regular physical activity can act as an anti-oxidant (Gomez-Cabrera et al. 2008), is related to better health (Shephard 1997; Warburton et al. 2006a, b), emotional well-being (Steptoe and Butler 1996) and that especially regular vigorous sports activities are related to mood improvement and stress reduction (Steptoe et al. 1998; for a review see Salmon 2001). In the long run, regular physical exercise has been related to lower mortality rates 
(Lee and Paffenbarger 2000). It has been estimated that it is best to spend about $10 \%$ sporting time compared to working time. For a work week of $40 \mathrm{~h}$, this means physical activities for about $4 \mathrm{~h}$ a week would be best. Even several short bouts of 10 min can be effective (Warburton et al. 2006b). As stress is the main cause of burn-out and diseases, it will certainly help if people are aware of the direct link between sport and stress reduction. Regular sports activity can thus mean that recovery during and after work is enhanced and this may mean staying energized at work (Thayer 1987a, b). Getting a new healthy habit is a matter of finding a ritual to do the action and get used to doing it by doing it often.

According to MacAuley (1993) it is relatively easy to integrate physical activity into daily life, by walking or cycling to work and including active tasks into everyday life, such as gardening. As work-related activity declines with modern living, the focus should be on sport and exercise which involve continuous aerobic movements, such as jogging, cycling, and swimming. However, for long-term compliance the most important principle is that the chosen activity is enjoyable (Parfitt and Gledhill 2004). Non-exercisers starting a work-out program should realize that most of the positive effects of regular exercise may only manifest themselves in the long-term (Hsiao and Thayer 1998; Salmon 2001; Steptoe and Bolton 1988).

Although most interventions occur at the individual level, a combination of changing the personal and managerial practices may be most effective (cf. Maslach et al. 2001). Although a lot of research is available regarding interventions at the individual level, interventions and research regarding the effect of interventions on the organizational level are scarce. A narrative of an intervention aimed at giving workers complete freedom of choice to work towards broad organizational goals suggested that this way of working can be highly effective both for the organization as well as the people in the organization (Semler 1989, 1994, see also Rousseau (1997). Relatedly, and mentioned before, research regarding the effects of different kinds of leadership, such as servant leadership (Barbuto and Wheeler 2006; Nuijten 2009) can be insightful with regard to the effects on energy on followers. Future research should look at the combination of individual, health related, as well as organizational factors in order to determine how a high energy level can be maintained or enhanced.

\section{Conclusion}

Although energy seems a pervading subject, that all people have to deal with on a daily basis, research regarding this topic is scarce. A lot of theories have an implicit energetic connotation, without explicitly relating it to energy. This review showed that much can be learned from motivational theories and research regarding interventions. Future research could focus more on the role of energy, and explicitly research the effects on human energy level. Possible antecedents and consequences of energy were mentioned in this article, such as personality and contextual factors. Also, the development and measurement of the effectiveness of interventions aimed at enhancing energy level deserves our research attention. In practice, people should become aware of the things that are energizing to them and capitalize on them more often. According to Csikszentmihalyi (1997, p. 40) energy level and flow can be enhanced as follows: "Keeping a diary or reflecting on the past day in the evening are ways to take stock systematically of the various influences on one's moods. After it is clear which activities produce the high points in one's day, it becomes possible to start experimenting, by increasing the frequency of the positive ones and decreasing that of others."

Open Access This article is distributed under the terms of the Creative Commons Attribution Noncommercial License which permits any noncommercial use, distribution, and reproduction in any medium, provided the original author(s) and source are credited.

\section{References}

Abramson, L. Y., Seligman, M. E. P., \& Teasdale, J. D. (1978). Learned helplessness in humans: Critique and reformulation. Journal of Abnormal Psychology, 87, 49.

Adams, G. A., \& Jex, S. M. (1999). Relationships between time management, control, work-family conflict, and strain. Journal of Occupational Health Psychology, 4, 72-77.

Ash, I. E. (1913). What makes a people lethargic or energetic? The American Journal of Sociology, 19(3), 370-379.

Bakker, A. B., Demerouti, E., \& Schaufeli, W. B. (2005). The crossover of burnout and work engagement among working couples. Human Relations, 58, 661-689.

Bakker, A. B., \& Heuven, E. (2006). Emotional dissonance, burnout, and in-role performance among nurses and police officers. International Journal of Stress Management, 13, 423-440.

Barbuto, J. E. J. R., \& Wheeler, D. W. (2006). Scale development and construct clarification of servant leadership. Group \& Organization Management, 31, 300-326.

Bass, B. M. (1985). Leadership and performance beyond expectations. New York: Free Press.

Bateman, T. S., \& Crant, J. M. (1993). The proactive component of organizational behavior: A measure and correlates. Journal of Organizational Behavior, 14, 103-118.

Brockner, J., \& Higgins, E. T. (2001). Regulatory focus theory: Implications for the study of emotions at work. Organizational Behavior and Human Decision Processes, 86, 35-66.

Brotheridge, C. M., \& Lee, R. T. (2003). Development and validation of the Emotional Labour Scale. Journal of Occupational \& Organizational Psychology, 76, 365-379.

Bruch, H., \& Ghoshal, S. (2002). Beware the busy manager. Harvard Business Review, 80, 62-69. 
Bruch, H., \& Ghoshal, S. (2003). Unleashing organizational energy. MIT Sloan Management Review, 45(1), 45-51.

Burke, L. A., \& Witt, L. A. (2004). Personality and high-maintenance employee behavior. Journal of Business and Psychology, 18, 349-363.

Calderwood, C. (2009). The role of trait neuroticism in predicting subjective fatigue states. Atlanta: Georgia Institute of Technology.

Chilton, M. A., Hardgrave, B. C., \& Armstrong, D. J. (2005). Personjob cognitive style fit for software developers: The effect on strain and performance. Journal of Management Information Systems, 22, 193-226.

Costa, P. T. J., \& McCrae, R. R. (1992). The NEO-PI-R: Revised Personality Inventory (NEO-PI-R). Odessa, FL: Assessment Resources.

Cross, R., Baker, W., \& Parker, A. (2003). What creates energy in organizations? MIT Sloan Management Review, 51-56.

Cross, R., \& Parker, A. (2004). Charged up: Creating energy in organizations. Journal of Organizational Excellence, 23, $3-14$.

Crowe, E., \& Higgins, E. T. (1997). Regulatory focus and strategic inclinations: Promotion and prevention in decision-making. Organizational Behavior and Human Decision Processes, 69, $117-132$.

Csikszentmihalyi, M. (1990). Flow: The psychology of optimal experience. New York: Harper Perennial.

Csikszentmihalyi, M. (1997). Finding flow. New York: Basic Books.

Csikszentmihalyi, M., \& LeFevre, J. (1989). Optimal experience in work and leisure. Journal of Personality and Social Psychology, $56,815-822$

DeNeve, K. M., \& Cooper, H. (1998). The happy personality: A metaanalysis of 137 personality traits and subjective well-being. Psychological Bulletin, 124, 197-229.

Diener, E. (1984). Subjective well-being. Psychological Bulletin, 95, $542-575$.

Diener, E., Suh, E. M., Lucas, R. E., \& Smith, H. L. (1999). Subjective well-being: Three decades of progress. Psychological Bulletin, 125, 276-302.

Edwards, J. R. (1991). Person-job fit: A conceptual integration, literature review and methodological critique. In C. L. Cooper \& I. T. Robertson (Eds.), International review of industrial/ organizational psychology (Vol. 6, pp. 283-357). New York: Wiley.

Eisenberger, N. I., Lieberman, M. D., \& Satpute, A. B. (2005). Personality from a controlled processing perspective: An fMRI study of neuroticism, extraversion, and self-consciousness. Cognitive, Affective \& Behavioral neuroscience, 5, 169-181.

Ericsson, K. A., Krampe, R. T., \& Tesch-Römer, C. (1993). The role of deliberate practice in the acquisition of expert performance. Psychological Review, 100, 363-406.

Ericsson, K. A., \& Lehmann, A. C. (1996). Expert and exceptional performance: Evidence and maximal adaptation to task constraints. Annual Review of Psychology, 47, 273.

Fisher, C. D. (1998). Effects of external and internal interruptions on boredom at work: Two studies. Journal of Organizational Behavior, 19, 503-522.

Fredrickson, B. L., \& Losada, M. F. (2005). Positive affect and the complex dynamics of human flourishing. American Psychologist, 60, 678-686.

Frese, M., \& Fay, D. (2001). Personal initiative: An active performance concept for work in the 21 st century. Research in Organizational Behavior, 23, 133-187.

Friedman, R. S., \& Förster, J. (2001). The effects of promotion and prevention cues on creativity. Journal of Personality and Social Psychology, 81, 1001-1013.
Gomez-Cabrera, M.-C., Domenech, E., \& Viña, J. (2008). Moderate exercise is an antioxidant: Upregulation of antioxidant genes by training. Free Radical Biology and Medicine, 44, 126-131.

Gonzalez-Roma, V., Schaufeli, W. B., Bakker, A. B., \& Lloret, S. (2006). Burnout and work engagement: Independent factors or opposite poles? Journal of Vocational Behavior, 68, 165-174.

Grandey, A. A. (2003). When "the show must go on": Surface acting and deep acting as determinants of emotional exhaustion and peer-rated service delivery. Academy of Management Journal, 46, 86-96.

Grensing-Pophal, L. (2001). High-maintenance employees. HR Magazine, 46, 86-91.

Hall, B. L., \& Hursch, D. E. (1982). An evaluation of the effects of a time management training program on work efficiency. Journal of Organizational Behavior Management, 3, 73-96.

Heaphy, E. D., \& Dutton, J. E. (2008). Positive social interactions and the human body at work: Linking organizations and physiology. Academy of Management Review, 33, 137-162.

Hewlin, P. F. (2003). And the award for best actor goes to: Facades of conformity in organizational settings. Academy of Management Review, 28, 633-642.

Higgins, E. T. (1998). Promotion and prevention: Regulatory focus as a motivational principle. In P. Z. Mark (Ed.), Advances in experimental social psychology (Vol. 30, pp. 1-46). New York: Academic Press.

Hobfoll, S. E. (1989). Conservation of resources: A new attempt at conceptualizing stress. American Psychologist, 44, 513-524.

Hsiao, E. T., \& Thayer, R. E. (1998). Exercising for mood regulation: The importance of experience. Personality and Individual Differences, 24, 829-836.

Jones, G. (2006). Coaching high achievers. Human Resource Management International Digest, 14, 3-4.

Joseph, B. (2000). Agreeableness as obstacle. International Journal of Psychological Analysis, 81, 641-649.

Judge, T. A., \& LePine, J. A. (2007). The bright and dark sides of personality: Implications for personnel selection in individual and team contexts. In J. L. Fox, G. Cooper, \& R. Klimoski (Eds.), Research companion to the dysfunctional workplace: management challenges and symptoms. Northampton, MA: Edward Elgar Publishing, Inc.

Kark, R., \& Van Dijk, D. (2007). Motivation to lead, motivation to follow: the role of the self-regulatory focus in leadership processes. Academy of Management Review, 32, 500-528.

Lam, D., Smith, S., Checkley, F., Rijsdijk, F., \& Sham, P. (2003). Effect of neuroticism, response style and information processing on depression severity in a clinically depressed sample. Psychological Medicine, 33, 469-479.

Lee, I. M., \& Paffenbarger, R. S., Jr. (2000). Associations of light, moderate, and vigorous intensity physical activity with longevity: The Harvard Alumni Health Study. American Journal of Epidemiology, 151, 293-299.

Leiter, M. P., \& Maslach, C. (1988). The impact of interpersonal environment on burnout and organizational commitment. Journal of Organizational Behavior, 9, 297-308.

Leiter, M. P., \& Maslach, C. (2000). Preventing burnout and building engagement: A complete program for organizational renewal. San Francisco: Jossey-Bass.

Macan, T. H. (1994). Time management: Test of a process model. Journal of Applied Psychology, 79, 381-391.

MacAuley, D. (1993). Exercise and health promotion. British Journal of General Practice, 43, 443-444.

Mark, G., Gonzalez, V. M., \& Harris, J. (2005). No task left behind? Examining the nature of fragmented work. Paper presented at the Conference on Human Factors in Computing Systems.

Maslach, C., \& Schaufeli, W. B. (1993). Historical and conceptual development of burnout. In W. B. Schaufeli, C. Maslach, \& 
T. Marek (Eds.), Professional burnout: Recent developments in theory and research (pp. 1-16). Washington, DC: Taylor \& Francis.

Maslach, C., Schaufeli, W. B., \& Leiter, M. P. (2001). Job burnout. Annual Review of Psychology, 52, 397.

Middleton, D. R. (1989). Emotional style: The cultural ordering of emotions. Ethos, 17(2), 187-201.

Mischel, W. (1996). From good intentions to willpower. In P. M. Gollwitzer \& J. A. Bargh (Eds.), The psychology of action: Linking cognition and motivation to behavior (Vol. 197-218). New York: Guilford Press.

Morris, J. A., \& Feldman, D. C. (1996). The dimensions, antecedents, and consequences of emotional labor. Academy of Management Review, 21, 986-1010.

Morrison, E. W., \& Phelps, C. C. (1999). Taking charge at work: Extrarole efforts to initiate workplace change. Academy of Management Journal, 42, 403-419.

Muraven, M., \& Baumeister, R. F. (2000). Self-regulation and depletion of limited resources: Does self-control resemble a muscle? Psychological Bulletin, 126, 247-259.

Nolan, S. A., Roberts, J. E., \& Gotlib, I. H. (1998). Neuroticism and ruminative response style as predictors of change in depressive symptomatology. Cognitive Therapy and Research, 22, 445-455.

Nuijten, I. (2009). Servant-leadership: Paradox or diamond in the rough? A multidimensional measure and empirical evidence. Unpublished Dissertation, Erasmus University Rotterdam, Rotterdam.

O'Conaill, B., \& Frohlich, D. (1995). Timespace in the workplace: Dealing with interruption. Paper presented at the Conference on Human Factors in Computing Systems.

Parfitt, G., \& Gledhill, C. (2004). The effect of choice of exercise mode on psychological responses. Psychology of Sport and Exercise, 5, 111-117.

Principe, L. (1997). The real cost of a bad hire. Network World, 14, 53-54.

Quinn, R. W., \& Dutton, J. E. (2005). Coordination as energyinconversation. Academy of Management Review, 30, 36-57.

Richardson, K. M., \& Rothstein, H. R. (2008). Effects of occupational stress management intervention programs: A meta-analysis. Journal of Occupational Health Psychology, 13, 69-93.

Roese, N. J., Hur, T., \& Pennington, G. L. (1999). Counterfactual thinking and regulatory focus: Implications for action versus inaction and sufficiency versus necessity. Journal of Personality and Social Psychology, 77, 1109-1120.

Rousseau, D. M. (1997). Organizational behavior in the new organizational era. Annual Review of Psychology, 48, 515.

Ryan, R. M., \& Frederick, C. (1997). On energy, personality, and health: Subjective vitality as a dynamic reflection of well-being. Journal of Personality, 65, 529-565.

Salmon, P. (2001). Effects of physical exercise on anxiety, depression, and sensitivity to stress: A unifying theory. Clinical Psychology Review, 21, 33-61.

Schaufeli, W. B., \& Bakker, A. B. (2004). Job demands, job resources, and their relationship with burnout and engagement: a multi-sample study. Journal of Organizational Behavior, 25, 293-315.

Schaufeli, W. B., Bakker, A. B., \& Salanova, M. (2006). The measurement of work engagement with a short questionnaire: A cross-national study. Educational and Psychological Measurement, 66, 701-716.

Schaufeli, W. B., Salanova, M., González-Romá, V., \& Bakker, A. B. (2002). The measurement of engagement and burnout: A two sample confirmatory factor analytic approach. Journal of Happiness Studies, 3(1), 71-92.
Schippers, M. C., Den Hartog, D. N., \& Koopman, P. L. (2007). Reflexivity in teams: A measure and correlates. Applied Psychology: An International Review, 56, 189-211.

Schippers, M. C., Den Hartog, D. N., Koopman, P. L., \& van Knippenberg, D. (2008). The role of transformational leadership in enhancing team reflexivity. Human Relations, 61, 1593-1616.

Schippers, M. C., \& Homan, A. C. (2009). Breaking the negative performance spiral: The role of team reflexivity and team learning. In Proceedings of the Sixty-Ninth Annual Meeting of the Academy of Management (online program).

Schippers, M. C., West, M. A., \& Dawson, J. F. (2010). Team reflexivity and innovation: The moderating role of team context. Paper presented at the Proceedings of the Seventieth Annual Meeting of the Academy of Management (CD), ISSN 1543-8643.

Seligman, M. E. P., \& Csikszentmihalyi, M. (2000). Positive psychology: An introduction. American Psychologist, 55, 5-14.

Semler, R. (1989). Managing without managers. Harvard Business Review, 67, 76-84.

Semler, R. (1994). Why my former employees still work for me. Harvard Business Review, 72, 64-71.

Shephard, R. J. (1997). What is the optimal type of physical activity to enhance health? British Journal of Sports Medicine, 31, 277-284.

Sonnentag, S. (1998). Expertise in professional software design: A process study. Journal of Applied Psychology, 83, 703-715.

Sonnentag, S. (2001). Work, recovery activities, and individual wellbeing: A diary study. Journal of Occupational Health Psychology, 6, 196-210.

Sonnentag, S. (2003). Recovery, work engagement, and proactive behavior: A new look at the interface between nonwork and work. Journal of Applied Psychology, 88, 518-528.

Spreitzer, G., Sutcliffe, K., Dutton, J., Sonenshein, S., \& Grant, A. M. (2005). A socially embedded model of thriving at work. Organization Science, 16, 537-549.

Stam, D. A., van Knippenberg, D., \& Wisse, B. (2010). The role of regulatory fit in visionary leadership. Journal of Organizational Behavior, 31, 499-518.

Steptoe, A., \& Bolton, J. (1988). The short-term influence of high and low intensity physical exercise on mood. Psychology \& Health, 2, 91-106.

Steptoe, A. S., \& Butler, N. (1996). Sports participation and emotional wellbeing in adolescents. The Lancet, 347, 1789-1792.

Steptoe, A., Kimbell, J., \& Basford, P. (1998). Exercise and the experience and appraisal of daily stressors: A naturalistic study. Journal of Behavioral Medicine, 21, 363-374.

Stone, G., Russell, R. F., \& Patterson, K. (2004). Transformational versus servant leadership: A difference in leader focus. Leadership \& Organization Development Journal, 25, 349-361.

Thayer, R. E. (1987a). Energy, tiredness, and tension effects of a sugar snack versus moderate exercise. Journal of Personality and Social Psychology, 52, 119-125.

Thayer, R. E. (1987b). Problem perception, optimism, and related states as a function of time of day (diurnal rhythm) and moderate exercise: Two arousal systems in interaction. Motivation and Emotion, 11, 19-36.

van der Hek, H., \& Plomp, H. N. (1997). Occupational stress management programmes: A practical overview of published effect studies. Occupational Medicine, 47, 133-141.

van Dierendonck, D., \& Nuijten, I. (in press). The servant leadership survey: Development and validation of a multidimensional measure. Journal of Business and Psychology. doi:10.1007/ s10869-010-9194-1

van Dierendonck, D., Schaufeli, W. B., \& Buunk, B. P. (1998). The evaluation of an individual burnout intervention program: The 
role of inequity and social support. Journal of Applied Psychology, 83, 392-407.

van Gelderen, B., Heuven, E., van Veldhoven, M., Zeelenberg, M., \& Croon, M. (2007). Psychological strain and emotional labor among police-officers: A diary study. Journal of Vocational Behavior, 71, 446-459.

Warburton, D. E. R., Nicol, C. W., \& Bredin, S. S. D. (2006a). Health benefits of physical activity: the evidence. Canadian Medical Association Journal, 174, 801-809.

Warburton, D. E. R., Nicol, C. W., \& Bredin, S. S. D. (2006b). Prescribing exercise as preventive therapy. Canadian Medical Association Journal, 174, 961-974.
West, M. A. (1996). Reflexivity and work group effectiveness: A conceptual integration. In M. A. West (Ed.), Handbook of work group psychology (pp. 555-579). Chichester: Wiley.

West, M. A. (2000). Reflexivity, revolution and innovation in work teams. In M. M. Beyerlein, D. A. Johnson, \& S. T. Beyerlein (Eds.), Product development teams (Vol. 5, pp. 1-29). Stamford, CT: JAI Press.

Yukl, G. (1998). Leadership in organizations (4th ed.). Upper Saddle River, NJ: Prentice-Hall. 